\section{RECENT RESEARCH}

Tooth loss linked to overall decline The memory and walking speeds of adults who have lost all of their teeth decline more rapidly than in those who still have some of their own teeth, according to new UCL research. ${ }^{1}$

The study looked at 3,166 adults aged 60 or over and compared their performance in memory tests and walking speed. The results showed that the people with none of their own teeth performed approximately $10 \%$ worse in both tests than the people with teeth. Tooth loss is therefore a potential early marker of decline in older age.

Rebuilding enamel

Scientists in Taiwan are developing a new biomaterial that can potentially rebuild worn enamel and reduce tooth sensitivity for an extended period. They describe the material, which is based on calcium and phosphorus and which they tested on dogs, in ACS Nano. ${ }^{2}$

1. Tsakos G, Watt R H, Rouxel P L, de Oliveira C, Demakakos P. Tooth loss associated with physical and cognitive decline in older adults. J Am Geriatr Soc 2015; 63: 91-99.

2. Chiang $Y C_{1}$ Lin $H \mathrm{P}$, Chang $\mathrm{H} \mathrm{H}$ et al. A mesoporous silica biomaterial for dental biomimetic crystallization. ACS Nano 2014; 8: 12502-12513.

\section{TH PREMIER SYMPOSIUM}

Over 250 dentists attended the 14th Premier Symposium jointly hosted by Dental Protection and schülke on 29 November 2014, for an insight into the challenges of complex clinical, ethical and dento-legal issues.

Dental Director at Dental

Protection, Kevin Lewis said: 'This year's conference provoked discussion around five important topical issues facing dentists: communication, patient medications, tooth wear, infection control and competency. Dentists are dedicated to providing exceptional clinical care, and we hope that we enhanced their skills and awareness to manage the ever-evolving landscape they will encounter throughout their careers'.

\title{
WORLD ORAL HEALTH DAY FOCUSES ON A SMILE FOR LIFE
}

As World Oral Health Day (WOHD) approaches on 20 March 2015, FDI World Dental Federation is advising people to consider the impact of frequent sugar consumption on their 'smile for life'.

Dental caries is the most common non-communicable disease in the world and research has clearly demonstrated that sugars are the main cause of tooth decay.

WOHD is an opportunity for FDI to draw attention to proven oral care behaviours that people can adopt to protect their teeth - for life. These include brushing twice a day with fluoride toothpaste, cutting down consumption of sugary foods and drinks between meals and chewing sugar-free gum after meals and snacks when on the go and brushing is not feasible.

FDI President Dr Tin Chun Wong said: "World Oral Health Day 2015: "Smile for life!" has a double meaning - lifelong smile and celebrating life. Smiling implies self-confidence and having fun, as people only smile if they are happy and have a healthy life. Please take the time to consider your oral health and bring a smile to everyone around you:

FDI supports the World Health Organisation's guidelines on reducing sugar consumption, based on evidence of its association with dental caries and obesity.

WOHD is celebrated throughout the world each year with a range of activities. For further information and resources, visit www.worldoralhealthday.org.

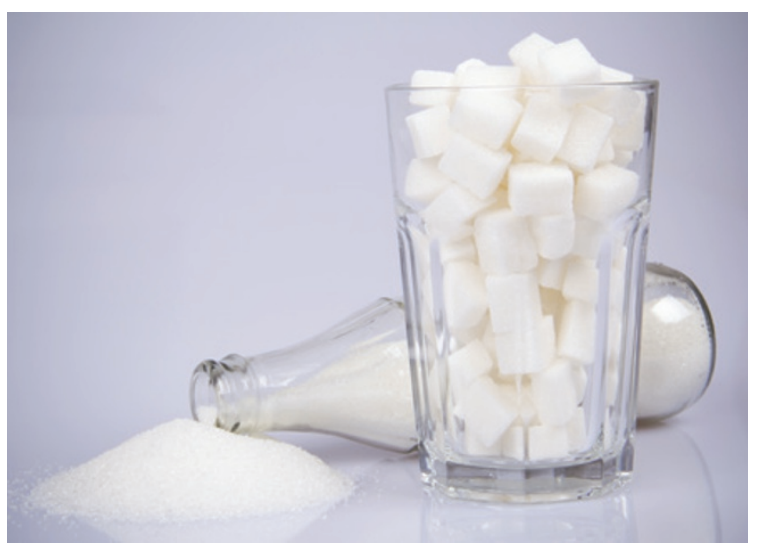

\section{BOOK REVIEW}

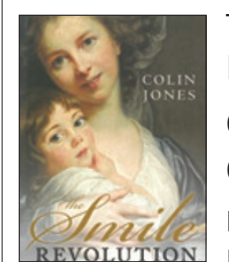

\section{THE SMILE REVOLUTION IN EIGHTEENTH CENTURY PARIS C. Jones \\ Oxford University Press price $£ 22.99$; pp 231 ISBN 9780198715818}

This is an interesting book written by Colin Jones, Professor of History at Queen Mary University of London. His passion for his subject is clear throughout the book and his knowledge on eighteenth century French healthcare is certainly expansive and impressive. He has paid attention to the artwork and literary texts of the times and described how the people, mainly women, were influenced by them.

This charming book is laid out in six chapters, with an additional post-script and handy 'notes' section which is referenced throughout the chapters. Mr Jones starts out by describing 'The Old Regime of Teeth' and the social etiquettes of the late seventeenth and early eighteenth centuries in the court of Louis XIV, with the smile being generally frowned upon, and many choosing to stay 'tight-lipped' due to the unattractiveness of tooth decay, gum disease, bad breath, or the dreaded 'black-hole'. The next chapter, 'The Smile of Sensibility', deals with the aftermath of King Louis XIV's death and the emergence of smiling in artwork and drama, which for the first time displayed teeth and brought with it an 'emblem of identity'. The chapter smoothly links onto the next and 'Cometh the Dentist' which heralds the advent of dentistry and the makings of the profession we would recognise today. The fourth chapter deals with the beginnings of the smile revolution with the new dentists more keen on providing preventative treatment in a surgery setting rather than the perceived quick-fix of an extraction by the infamous tooth pullers on the Pont Neuf. The final two chapters cover the arrival of the revolution in 1789 which unfortunately was to be short lived as by 1793 jovial smiles were disappearing due to the advent of the Terror. Life was to continue this way until the twentieth century revolutionary comeback led by the USA and the emergence of 'Hollywood' smiles.

All in all, this book is well written, clearly well researched and nicely presented with the occasional illustration. I would say it is aimed at those interested in the history of dentistry and how we, as a profession, came to be, and as such could be assumed to be for a niche market. In an age where everyone is after the 'Hollywood' smile, it is interesting to read through the origins of a smile that was once so elusive. A fascinating read.

c. FORSYTH 